\title{
Pengaruh Penerapan Model Evaluasi Praktik Klinik terhadap Pencapaian Tahapan Kompetensi Asuhan Persalinan Mahasiswa D III Kebidanan
}

\author{
Indah Yulika, ${ }^{1}$ Dany Hilmanto, ${ }^{2}$ Farid Husin, ${ }^{3}$ Johanes C. Mose, ${ }^{4}$ Ishak Abdulhak, ${ }^{5}$ Anita D. Anwar ${ }^{6}$ \\ ${ }^{1}$ Mahasiswa Program Studi Magister Kebidanan Fakultas Kedokteran Universitas Padjadjaran \\ ${ }^{2}$ Departemen Ilmu Kesehatan Anak Fakultas Kedokteran Universitas Padjadjaran \\ ${ }^{3}$ Departemen Epidemiologi dan Biostatistika Fakultas Kedokteran Universitas Padjadjaran \\ ${ }^{4,6}$ Departemen Obstetri dan Ginekologi Fakultas Kedokteran Universitas Padjadjaran \\ ${ }^{5}$ Program Studi Pengembangan Kurikulum Sekolah Pasca Sarjana Universitas Pendidikan Indonesia
}

\begin{abstract}
Abstrak
Setiap mahasiswa akan mampu menguasai kompetensi jika diberi waktu sesuai dengan kebutuhannya. Model evaluasi praktik klinik berdasarkan pembelajaran tuntas dan tahapan pembelajaran motorik dimaksudkan agar dapat mengidentifikasi kompetensi sehingga pembelajaran dilakukan dengan tepat.Tujuan penelitian ini adalah menganalisis pengaruh penerapan model evaluasi praktik klinik terhadap pencapaian tahapan kompetensi asuhan persalinan (kesiapandiri, sub kompetensi dan kompetensi komprehensif) mahasiswa kebidanan.Penelitian ini menggunakan rancangan kuasi eksperimen dengan posttest-only with nonequivalent control groups.Subjek dibagi menjadi 2 kelompok, yaitu 27 orang kelompok perlakuan dan 26 orang kelompok kontrol.Kelompok perlakuan menerapkan model evaluasi praktik klinik, sedangkan kelompok kontrolhanya menggunakan alat evaluasi tanpa menerapkan model evaluasi.Tempat penelitian dilakukan di RSUD Soreang dan RSUD Majalaya padabulan September-Desember 2015.Hasil penelitian mendapatkan pencapaian kompetensi asuhan persalinan pada tahap pemula kelompok perlakuan sebesar $89 \%$, tahap transisi $56 \%$ dan tahap mandiri $41 \%$.Sementara pada kelompok kontrol pencapaian kompetensi pada tahap pemula dan transisi adalah $0 \%$, dan pencapaian tahap mandiri hanya $4 \%$.Dengan demikian terdapat perbedaan pencapaian kompetensi yang bermakna pada tiap tahapan pembelajaran antara kelompok perlakuan dan kontrol $(\mathrm{p}<0.05)$.Simpulan pada penelitian ini adalah model evaluasi praktik klinik berpengaruh terhadap pencapaian tahapan kompetensi asuhan persalinan pada mahasiswa D III Kebidanan.
\end{abstract}

Kata kunci: Praktik klinik, model evaluasi, tahapan kompetensi 


\title{
The Effect of Evaluation Model of Clinical Practice Achieving the Stage of Delivery Care
}

\begin{abstract}
Evaluation model of clinical practice is developed based on the stages of motoric learning.The preceptors can identify mastery the sub unit of competence and the stages level of motoric learning so that the learning can be done properly. The aim of this study was to analyze the application of an evaluation model of clinical practice to the achievement of delivery care competence of midwifery student (preparedness, mastery of sub competence and mastery of comprehensive competence). This research design was a quasi-experimental posttest-only with nonequivalent control groups. Subjects were divided into 2 groups: the treatment group were 27 and the control group were 26 students. The treatment group applying the model of evaluation of clinical practice, while the control group only use the evaluation tool without applying the model. The research conducted in Soreang and Majalaya hospitals in September-December 2015. The results showed that achievement of delivery care competence in the treatment group at the beginner, transition, and independent stage was $89 \%, 56 \%$ and $41 \%$, whereas in the control group it was $0 \%$ at the beginner and transition, and only $4 \%$ at the independent stage. There were significant differences in the achievement of competence at each stage of learning between treatment and control group $(\mathrm{p}<0.05)$. Evaluation model of clinical practice proved to have an impact on the attainment of three stages of clinical practice learning $(p<0.001)$. In conclusions, the evaluationmodels of clinical practice affectsthe achievement of the stages of delivery care competence of midwifery students.
\end{abstract}

Keywords: Clinical practice, evaluation model, stage of competence

\section{Pendahuluan}

Bidan diakui sebagai tenaga profesional yang akuntabel untuk memberikan asuhan dalam masa kehamilan, persalinan, nifas serta bayi baru lahir. ${ }^{1,2}$ Kompetensi asuhan persalinan dapat dicapai melalui proses pembelajaran dan evaluasi praktik klinik yang baik. Evaluasi praktik klinik merupakan sebuah proses untuk menentukkan tercapai tidaknya kompetensi mahasiswa dalam praktik. $^{3}$ Bondy (1994) menyebutkan bahwa evaluasi kinerja klinis mahasiswa di lahan praktik seringkali menimbulkan masalah. ${ }^{4}$ Hasil penelitian yang dilakukan di Iran tahun 2004 mendapatkan sebanyak $77 \%$ mahasiswa merasa tidak puas terhadap metode evaluasi praktik klinik dan meminta kepada pembimbing mereka untuk membuat metode evaluasi yang baru. ${ }^{5-7}$

Pada banyak penelitian bidang pendidikan tenaga kesehatan tentang mastery learning atau belajar tuntas, didapatkan bahwa jumlah siswa yang kompeten meningkat tajam dengan pembelajaran dan evaluasi berbasis belajar tuntas. Tang dan Dong (2013) mendapatkan bahwa $83 \%$ perawat mencapai nilai baik dan $16 \%$ mencapai nilai baik sekali pada program pelatihan asuhan perawatan dasar dengan mengaplikasikan pembelajaran tuntas. Para perawat tersebut juga didapatkan menjadi semakin percaya diri dalam melakukan prosedur asuhan perawatan dasar dan para dokter juga lebih percaya kepada kemampuan mereka. ${ }^{8}$

Kompetensi klinik asuhan persalinan merupakan kemampuan melakukan keterampilan motorik asuhan persalinan yang didasari oleh pengetahuan dan diiringi dengan sikap yang baik.Terdapat beberapa tahapan dalam pembelajaran motorik. Setiap tahapan merupakan rangkaian pembelajaran yang memiliki tujuan penguasaan keterampilan/kompetensi. ${ }^{9}$ Evaluasi ketercapaian kompetensi hendaknya dilakukan secara individual. Hal ini dimaksudkan agar masing-masing individu dapat diamati dan dinilai secara pasti sejauh mana kemampuan dan keterampilannya dalam melaksanakan tugas yang diberikan. ${ }^{10}$

Model evaluasi praktik klinik berdasarkan tahapan pembelajaran motorik pada pembelajaran asuhan persalinan dapat dilakukan melalui pendekatan mastery learning atau belajar tuntas.Belajar tuntas bersifat individual. Konsep belajar tuntas dilandasi pandangan bahwa setiap mahasiswa akan mampu menguasai kompetensi jika diberi waktu sesuai dengan kebutuhannya. Pendekatan ini membutuhkan waktu yang cukup dan proses pembelajaran yang berkualitas. ${ }^{11}$ Model evaluasi berdasarkan pendekatan belajar tuntas bersifat formatif akan menghasilkan 
umpan balik agar dapat sesegera mungkin mengidentifikasi pencapaian kompetensi siswa pada setiap tahapan pembelajaran keterampilan.Tujuan penelitian ini adalah menganalisis pengaruh penerapan model evaluasi praktik klinik terhadap pencapaian kompetensi asuhan persalinan pada tiap tahap pembelajaran (kesiapan diri, penguasaan sub kompetensi dan kompetensi komprehensif) mahasiswa D III Kebidanan.

\section{Metode}

Penelitian ini akan menggunakan desain quasi experiment dengan rancangan posttest-only with nonequivalent control groups. Subjek dibagi menjadi 2 kelompok yaitu kelompok perlakuan dan kelompok kontrol.Subjek dibagi menjadi 2 kelompok, yaitu 27 orang kelompok perlakuan dan 26 orang kelompok kontrol.Kelompok perlakuan menerapkan model evaluasi praktik klinik, sedangkan kelompok kontrol hanya menggunakan alat evaluasi pengukuran kompetensi tanpa menerapkan model evaluasi. Kelompok perlakuan adalah mahasiswa yang melakukan praktik klinik persalinan di RSUD
Majalaya, sedangkan kelompok kontrol merupakan mahasiswa yang melakukan praktik klinik di RSUD Soreang. Waktu penelitian dilakukan pada bulan September sampai dengan Desember 2015.

Penelitian ini dilakukan pada 14 hari pembelajaran praktik klinik asuhan persalinan.Pengukuran awal bertujuan untuk menilai kesiapan mahasiswa untuk melakukan praktik klinik dengan mengunakan format evaluasi tahap pemula. Pengukuran selanjutnya bertujuan untuk mengevaluasi peningkatan penguasaan sub kompetensi pada tahap transisi dan kompetensi asuhan persalinan komprehensif pada tahap mandiri. Pengukuran setiap tahap pembelajaran pada kelompok kontrol dilakukan ketika sebagian besar mahasiswa pada kelompok perlakuan telah mencapai kompetensi yang ditetapkan.Pada penelitian ini didapatkan sebagian besar kelompok perlakuan telah mencapai kompetensi tahap pembelajaran pemula pada hari ke-2, tahap transisi pada hari ke-10, dan tahap mandiri pada hari ke-14.

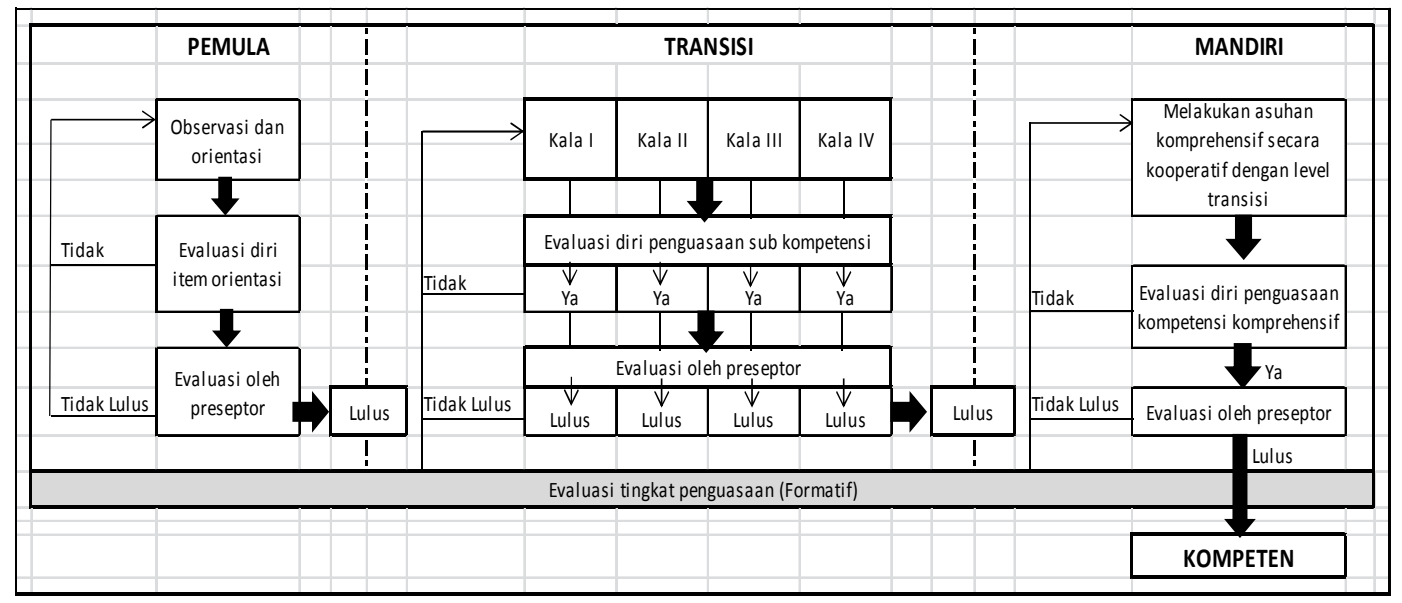

Gambar Bagan Mekanisme model evaluasi praktik klinik

Analisis univariat dilakukan untuk mendapatkan gambaran statistik karakteristik responden.Analisis bivariat dilakukan untuk menganalisis hubungan antar variabel penelitian.Penentuan jenis analisis didasarkan pada jenis data atau skala pengukuran variabel. Analisis yang digunakan adalah uji $\mathrm{T}$ tidak berpasangan, mann whitney, chi-square, manova dan uji mancova.

IJEMC, Volume 3 No. 1, Maret 2016|23

\section{Hasil}

Perbedaan karakteristik subjek dapat mempengaruhi hasil penelitian.Nilai indeks prestasi dan motivasi disebut dalam beberapa kajian jurnal dapat memprediksi pencapaian kompetensi pembelajaran siswa.Demikian juga subjek pada penelitian ini adalah mahasiswa yang telah memiliki pengalaman belajar praktik klinik asuhan persalinan sebelumnya di bidan praktik mandiri dan puskesmas, seperti yang terlihat pada tabel 1 . 
Tabel 1 Karakteristik subjek penelitian

\begin{tabular}{cccc}
\hline Karakteristik & Kelompok & & Nilai p \\
\hline Indeks Prestasi & Kerlakuan $(\mathbf{n}=\mathbf{2 7})$ & Kontrol (n= 26) & \\
Median (range) & $3.61(3.14-4.00)$ & $3.13(2.70-3.65)$ & $<0.001^{*}$ \\
Mean (sd) & $3.59(0.22)$ & $3.13(0.19)$ & $<0.001^{*}$ \\
Motivasi awal & & & \\
Median (range) & $68.98(48.15-81.48)$ & $61.57(50-75)$ & $0.358^{* *}$ \\
Mean (sd) & $68.93(7.40)$ & $61.53(6.78)$ & \\
Kompetensi awal & $66.13(35-87)$ & $72.58(21-90)$ & $67.12(17.09)$ \\
Median (range) & $65.51(13.37)$ & & \\
Mean (sd) & & &
\end{tabular}

Keterangan : *)Uji T Tidak Berpasangan; **)Uji Mann Whitney

Pada tabel 1 terlihat bahwa kedua kelompok Pencapaian kompetensi yang ditetapkan pada memiliki kompetensi asuhan persalinan yang penelitian ini adalah perolehan nilai mutlak pada setara pada pengukuran awal sebelum intervensi pengukuran tiap tahapan pembelajaran.Hasil diberikan pada kelompok perlakuan( $\mathrm{p}>$ pengukuran pada tiap tahapan yang dibandingkan 0.05).Sedangkan pada indeks prestasi dan adalah frekuensi ketika sebagian besar motivasi pembelajaran terdapat perbedaan yang mahasiswa pada kelompok perlakuan telah bermakna antara kedua kelompok, sehingga mencapai kompetensi tahapan pembelajaran perlu dilakukan analisis lanjutan untuk yang ditetapkan, yaitu tahap pemula hari ke-2 mengetahui bagaimana peran indeks prestasi dan praktik klinik, tahap transisi pada hari ke-10, dan motivasi dalam pencapaian kompetensi asuhan tahap mandiri pada hari ke-14. persalinan.

Tabel 2Perbedaan pencapaian kompetensi asuhan persalinan pada tiap tahapan pembelajaran kedua kelompok

\begin{tabular}{|c|c|c|c|c|}
\hline \multirow{2}{*}{ Variabel } & \multicolumn{2}{|c|}{ Pencapaian Kompetensi } & \multirow{2}{*}{ Total } & \multirow{2}{*}{ Nilai $p$} \\
\hline & Kompeten & Tidak Kompeten & & \\
\hline \multicolumn{5}{|l|}{ Pemula (hari ke-2) } \\
\hline Perlakuan & $24(89 \%)$ & $3(11 \%)$ & 27 & \multirow{2}{*}{$<0.001$} \\
\hline Kontrol & $0(0 \%)$ & $26(100 \%)$ & 26 & \\
\hline \multicolumn{5}{|l|}{ Transisi (hari ke-10) } \\
\hline Perlakuan & $15(56 \%)$ & $12(44 \%)$ & 27 & \multirow{2}{*}{$<0.001$} \\
\hline Kontrol & $0(0 \%)$ & $26(100 \%)$ & 26 & \\
\hline \multicolumn{5}{|l|}{ Mandiri (hari ke-14) } \\
\hline Perlakuan & $11(41 \%)$ & $16(59 \%)$ & 27 & \multirow{2}{*}{0.002} \\
\hline Kontrol & $1(4 \%)$ & $25(96 \%)$ & 26 & \\
\hline
\end{tabular}

Keterangan : *) Uji Chi-Square

Hasil penelitian pencapaian kompetensi asuhan persalinan pada tahap pemula kelompok perlakuan sebesar $89 \%$, tahap transisi $56 \%$ dan tahap mandiri $41 \%$.Sementara pada kelompok kontrol pencapaian kompetensi pada tahap pemula dan transisi adalah $0 \%$, demikian juga pencapaian tahap mandiri hanya $4 \%$.Ada perbedaan pencapaian kompetensi pada tiap

tahapan pembelajaran antara kelompok perlakuan dan kontrol $(\mathrm{p}<0.05)$.

Pengaruh model evaluasi praktik klinik terhadap pencapaian kompetensi dilakukan dengan menggunakan Manova dipilih karena dapat menganalisis interaksi model evaluasi dengan pencapaian kompetensi tiap tahapan pembelajaran secara simultan seperti yang dapat dilihat pada tabel 3 berikut ini.

Tabel 3 Pengaruh model evaluasi praktik klinik terhadap pencapaian kompetensi asuhan persalinantiap tahapan pembelajaran

24|IJEMC, Volume 3 No. 1, Maret 2016 


\begin{tabular}{lccc}
\hline \multirow{2}{*}{ Variabel } & Perlakuan $(\mathbf{n}=\mathbf{2 7})$ & Kontrol $(\mathbf{n}=\mathbf{2 6})$ & \multirow{2}{*}{ Nilai $\boldsymbol{p}$} \\
\cline { 2 - 3 } & Mean (sd) & Mean (sd) & $>\mathbf{0 . 0 0 1}$ \\
Pemula & $96.94(8.7)$ & $70.05(1.85)$ & $\mathbf{0 . 0 0 2}$ \\
Transisi & $86.61(1.82)$ & $73.50(1.19)$ & $\mathbf{0 . 0 0 1}$ \\
Mandiri & $84.11(1.71)$ & $69.90(1.45)$ & \\
\hline
\end{tabular}

Keterangan : Uji Manova, Hotelling’s Trace: nilai $\mathrm{p}<0.001$, Wilks’ Lambda $=0.460$

Berdasarkan hasil tersebut didapatkan bahwa dengan memperhitungkan korelasi antara variabel dependen,model evaluasi praktik klinik berpengaruh terhadap pencapaian tahapan kompetensi asuhan persalinan mahasiswa D III Kebidanan (Hotelling's Trace: $p<0.001$ ).
Kemudian untuk mengetahui bagaimana peran nilai indeks prestasi dan motivasi belajar terhadap pencapaian kompetensi tiap tahapan pembelajaran asuhan persalinan dilakukan analisis dengan menggunakan uji mancova, seperti terlihat pada tabel 4 dan 5 .

Tabel 4Analisis multivariat pencapaian kompetensi asuhan persalinan tiap tahapan pembelajaran dengan mengontrol pengaruh indeks prestasi

\begin{tabular}{lccc}
\hline \multirow{2}{*}{ Variabel } & Perlakuan $(\mathbf{n}=\mathbf{2 7})$ & Kontrol $(\mathbf{n}=\mathbf{2 6})$ & \multirow{2}{*}{ Nilai $\boldsymbol{p}$} \\
\cline { 2 - 3 } & Mean (sd) & Mean (sd) & $>\mathbf{0 . 0 0 1}$ \\
Pemula & $96.94(8.7)$ & $70.05(1.85)$ & $\mathbf{0 . 0 3 7}$ \\
Transisi & $86.61(1.82)$ & $73.50(1.19)$ & $\mathbf{0 . 0 2 9}$ \\
Mandiri & $84.11(1.71)$ & $69.90(1.45)$ & \\
\hline
\end{tabular}

Keterangan : Uji Mancova, F Hotelling $=0.061$, nilai $p=0.980$, Wilks' Lambda $=0.632$

Tabel 5Analisis multivariat pencapaian kompetensi asuhan persalinan tiap tahapan pembelajaran dengan mengontrol pengaruh nilai motivasi

\begin{tabular}{lccc}
\hline \multirow{2}{*}{ Variabel } & Perlakuan $(\mathbf{n}=\mathbf{2 7})$ & Kontrol $(\mathbf{n}=\mathbf{2 6})$ & \multirow{2}{*}{ Nilai $\boldsymbol{p}$} \\
\cline { 2 - 3 } & Mean (sd) & Mean (sd) & \\
\hline Pemula & $96.94(8.7)$ & $70.05(1.85)$ & $\mathbf{0 . 0 0 1}$ \\
Transisi & $86.61(1.82)$ & $73.50(1.19)$ & $\mathbf{0 . 0 9}$ \\
Mandiri & $84.11(1.71)$ & $69.90(1.45)$ & $\mathbf{0 . 0 4}$ \\
\hline
\end{tabular}

Keterangan : Uji Mancova, F Hotelling $=3.598$, nilai $p=0.020$, Wilks' Lambda $=0.581$

Berdasarkan tabel 4 dan 5 diatas, pada penelitian mekanisme evaluasi yang bersifat ini didapatkan bahwa indeks prestasi tidak formatif.Prosedur pembelajaran dilakukan memiliki pengaruh terhadap pencapaian melalui modifikasi atas dasar hasil evaluasi dan kompetensi, sementara motivasi memiliki cukup kemajuan yang dicapai siswa. Evaluasi ini peran dalam menunjang penerapan model kemudian diiringi dengan umpan balik yang evaluasi untuk mencapai kompetensi, terutama dimungkinkan dilakukan terhadap tiap pada tahap transisi.

\section{Pembahasan}

Evaluasi praktik klinik merupakan sebuah proses untuk menentukan tercapai tidaknya kompetensi mahasiswa dalam praktik. ${ }^{3}$ Evaluasi dibutuhkan untuk peningkatan dalam pembelajaran klinik atau berfungsi sebagai penilaian formatif. Penilaian formatif memberikan kesempatan siswa dan guru untuk melakukan umpan balik apakah materi pembelajaran telah dikuasai atau belum.Konsep pembelajaran tuntas (mastery learning) dapat juga diterapkan dalam lingkup poin/langkah pada tiap tahapan pembelajaran secara sistematis, bervariasi dan sesegera mungkin pada saat respon siswa terjadi. ${ }^{9}$

Siswa berkembang pada kecepatan yang berbeda-beda, bereaksi terhadap pasien dengan cara berbeda, dan dapat memiliki variasi keterampilan dari waktu ke waktu. Semua siswa berada dalam serangkaian perkembangan kemampuan mulai dari sebagai pemula hingga menjadi seorang ahli. ${ }^{12}$ Sesuaidengankonsep pembelajaran tuntas, rancangan model evaluasi dimulai memecah rangkaian pembelajaran 
Indah Yulika: Pengaruh Penerapan Model Evaluasi Praktik Klinik terhadap Pencapaian Tahapan Kompetensi Asuhan Persalinan Mahasiswa D III Kebidanan

kompetensi praktik asuhan persalinan menjadi tiga tahapan yaitu tahap pemula untuk menilai kesiapan belajar, tahap transisi untuk menilai penguasaan sub kompetensi sesuai dengan kala dalam persalinan, dan tahap mandiri untuk menilai penguasaan kompetensi secara komprehensif. Pelaksanaan evaluasi dilakukan berdasarkan kesiapan siswa pada tiap tahapan pembelajaran motorik dan penguasaan sub kompetensi. Siswa yang belum menguasai sub kompetensi tertentu dapat mengulangi pembelajaran dan kemudian dievaluasi kembali.Pengukuran tahap pemula dapat dilakukan mulai hari pertama, kemudian bertahap level transisi dan level mandiri sesuai dengan kecepatan siswa.

Mekanisme model evaluasi yang dikembangkan ini disusun untuk mendukung proses pada tiap tahapan pembelajaran. Rumusan model evaluasi dirancang untuk dicapai secara bertahap secara berkesinambungan. Evaluasi yang dilakukan secara berkesinambungan akan dapat memantau tahapan pembelajaran yang telah dapat diselesaikan, dan tahapan pembelajaran yang mengalami kendala. Mekanisme evaluasi tersebut dapat membuka peluang bagi pembimbing untuk menganalisis kemampuan siswa sedini mungkin dan kemudian dengan segera melakukan perbaikan proses pembelajaran sesuai kemampuan siswa. Perbaikan proses pembelajaran tersebut tidak mungkin dilakukan tanpa kegiatan evaluasi, karena untuk melakukan perbaikan harus diketahui dahulu hal apa yang harus diperbaiki. Kegiatan evaluasi yang tidak dapat menghasilkan umpan balik untuk perbaikan adalah tidak bermakna. ${ }^{10}$

Hasil penelitian mendapatkan pencapaian kompetensi asuhan persalinan pada tahap pemula kelompok perlakuan sebesar $89 \%$, tahap transisi $56 \%$ dan tahap mandiri $41 \%$.Sementara pada kelompok kontrol pencapaian kompetensi pada tahap pemula dan transisi adalah $0 \%$, demikian juga pencapaian tahap mandiri hanya 4\%.Terdapat perbedaan pencapaian kompetensi yang bermakna pada tiap tahapan pembelajaran antara kelompok perlakuan dan kontrol $(\mathrm{p}<$ 0.05).Kemudian dengan menggunakan uji manova didapatkan bahwa model evaluasi praktik klinik terbukti memiliki pengaruh terhadap pencapaian kompetensi tiga tahap pembelajaran praktik klinik $(\mathrm{p}<0.001)$.

Hasil uji mancova untuk menganalisis variabel perancu mendapatkan bahwa motivasi memiliki pengaruh terhadap pencapaian kompetensi asuhan persalinan pada tiap tahapan pembelajaran $(p<0.05)$, sedangkan indeks prestasi tidak. Bloom (1968) menyatakan bahwa pada pembelajaran tuntas tidak terdapat korelasi antara kecerdasan dengan pencapaian kompetensi. ${ }^{13}$ Sedangkan motivasi memiliki cukup peran pada pencapaian kompetensi. Model evaluasi ditunjang dengan motivasi yang tinggi akan menghasilkan hasil yang baik. Penerapan model evaluasi praktik klinik pada pengembangan sistem pembelajaran praktik klinik memiliki pengaruh $17 \%$ menyebabkan mahasiswa mencapai kompetensi asuhan persalinan tiap tahapan pembelajaran (Wilks' Lambda $=0.581)$.

Raisler dkk (2003) mengkaji berbagai bahan pengajaran dan mendapatkan bahwa sebagain besar menekankan pentingnya orientasi klinik sebelum pembelajaran. ${ }^{14}$ Orientasi terprogram dapat membantu siswa mempersiapkan dirinya sebelum benar-benar terjun belajar menghadapi pasien dan segala kesibukan rumah sakit.Sehingga diharapkan mahasiswa menjadi percaya diri, pembelajaran dapat berjalan efektif, dan aktivitas rumah sakit tidak terganggu.Dalam waktu tiga hari, keseluruhan mahasiswa pada kelompok perlakuan telah dapat menguasai tugas orientasi tahap pemula yang diberikan.Serta juga didapatkan waktu median 8 hari untuk menyelesaikan tahap transisi dan 4 hari untuk menyelesaikan tahap mandiri.Waktu tersebut dapat saja berbeda sesuai dengan kemampuan dan kecepatan masing-masing siswa.

Kompetensi merupakan fungsi dari waktu belajar yang disediakan berhubungan lurus dengan waktu yang dibutuhkan.Lamanya waktu yang dibutuhkan dipengaruhi oleh bakat/ kecerdasan siswa, kualitas pembelajaran, dan kemampuan siswa memahami pembelajaran.Sedangkan efektifnya waktu yang disediakan dipengaruhi oleh ketekunan siswa, dan kesempatan belajar. Kesadaran akan perbedaan kecepatan pembelajaran siswa menjadi dasar perlunya perubahan besar pada sistem pembelajaran 
Indah Yulika: Pengaruh Penerapan Model Evaluasi Praktik Klinik terhadap Pencapaian Tahapan Kompetensi Asuhan Persalinan Mahasiswa D III Kebidanan

praktik klinik. Dengan didukung sistem pembelajaran yang baik, maka diharapkan motivasi belajar siswa akan dapat meningkat dan proses pembelajaran praktik klinik akan berjalan dengan optimal, sehingga mengahasilkan mahasiswa yang kompetensi dan siap untuk memenuhi kebutuhan masyarakat.

\section{Simpulan}

Keberhasilan pembelajaran praktik klinik merupakan tanggung jawab semua pihak yang terlibat dalam pendidikan dan pelayanan kesehatan.Dibutuhkan perubahan yang besar dalam sistem pembelajaran praktik klinik kebidanan agar dapat mencapai harapan dihasilkannya bidan professional yang sesuai dengan kebutuhan masyarakat, termasuk model evaluasi.Model evaluasi praktik klinik berdasarkan pembelajaran tuntas dan tahap pembelajaran motorik pada penelitian ini terbukti memiliki peran dalam pencapaian kompetensi asuhan persalinan pada mahasiswa D III Kebidanan.

\section{Daftar Pustaka}

1. Fullerton JT, Gherissi A, Johnson PG, Thompson JB. Competence and competency: core concepts for international midwifery practice. International Journal of Childbirth. 2011;1(1):4 - 12.

2. Keputusan Menteri Kesehatan Republik Indonesia Nomor 369/Menkes/SK/III/2007 tentang Standar Profesi Bidan, (2007).
3. Zafrir $\mathrm{H}$, Nissim S. Evaluation in clinical practice using an innovative model for clinical teachers. Journal of Nursing Education. 2011;50(3):167 - 71.

4. Krichbaum K, Rowan M, Duckett L, Ryden MB, Savik $K$. The clinical evaluation tool: a measure of the quality of clinical performance of baccalaureate nursing student. Journal of Nursing Education. 1994;33(9):395-404.

5. Khadivzade T, Farzi F. The investigation of the weakness and strengths of clinical education from the viewpoints of nursing and midwifery student in Mashad in 2003. Iranian J Medical Education. 2004;10:67.

6. Hadizadeh F, Firoozi M. Shamaeyan Razavi Nursing and Midwifey Student Perspective on Clinical Education in Gonabad University of Medical Sciences. Iranian J Medical Education. 2005;1(5):70 - 8.

7. Yaghobian M, Fakhri M, Salmeh F, Yaghobi T, Zakizad M, Shahmohammadi S. Assessment of the log book on nursing and midwifery student's clinical skills. Middle-East Journal of Scientific Research. 2011;7(6):896-902.

8. Tang WE, Dong L. Applying Mastery Learning in a Clinical Skills Training Program for Primary Care Nurses. The Journal of Continuing Education in Nursing. 2013;44(12).

9. Rahyubi H. Teori-teori belajar dan aplikasi pembelajaran motorik. Bandung: Nusa media; 2012.

10. Sudijono A. Pengantar evaluasi pendidikan. Jakarta: RajaGrafindo Persada; 2013.

11. Hernawan AH. Makna ketuntasan dalam belajar.

12. Burns C, Beauchesne M, Ryan-Krause P, Sawin K. Mastering the Preceptor Role: Challenges of Clinical Teaching. Jounal of Pediatric Health Care. 2006;20(3):172-83.

13. Bloom BS. Learning for mastery. Center for the study evaluation of instructional programs. 1968;1(2).

14. Raisler J, O'Grady M, Lori J. Clinical Teaching and Learning in Midwifery and Women's Health. Journal of Midwifery \& Women's Health. 2003;48(6). 